\title{
El Xingyiquan estilo Che en Taiwan según las enseñanzas del Dr. Wu Chaoxiang
}

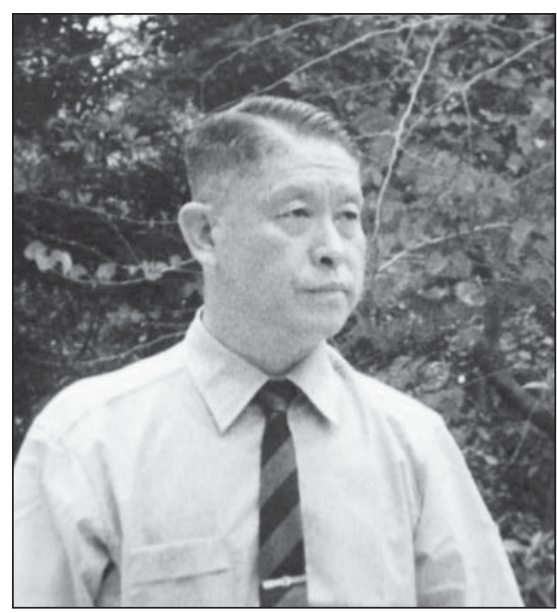

El Dr. Wu Chaoxiang (1917-2000).

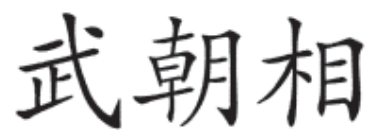

El edificio de los juzgados Yuan, bloqueado parcialmente por una sección del Hospital Nacional

Universitario de Taiwan.

Fotografía tomada el 2 de julio de 2005 por Allen Timothy Chang.

(página siguiente)

El Dr. Wu Chaoxiang realiza una técnica imitando la acción de un mono.

Todas las fotografías son cortesía de S. Henning excepto aquellas en las que se indique lo contrario.

\author{
Stanley E. Henning
}

Aprender Xingyiquan del Dr. Wu Chaoxiang (Wu Chao-hsiang, 1917-2000), en Taiwan, entre 1971 y 1972, fue para mí una experiencia vital clarificadora. El Dr. Wu era de la provincia de Shanxi, el hogar del Xingyiquan. Fue estudiante con el Sr. Bu Xuekuan (1876-1971), de la comarca de Taigu. El maestro Bu estudió con Che Yizhai (1833-1914), cuyo nombre familiar se asocia con su estilo particular de Xingyiquan. El Dr. Wu enseñó su estilo Shanxi Che, uno de los tres estilos dominantes de Xingyiquan, siendo los otros el estilo Hebei y el estilo Henan.

El Dr. Wu era uno de los muchos chinos continentales que se reunían cada domingo en el patio de los viejos juzgados Yuan (literalmente "juzgado para el establecimiento de justicia") en Taipei para conversar y transmitir sus conocimientos a una interesada joven generación. Ellos representaban el corazón de la comunidad de artes marciales de China continental que emigró a Taiwan en 1949. Como tales, ofrecían una rica sección transversal de los variados estilos practicados en China. Entre ellos estaba el Sr. Ju Hao, quien había estudiado

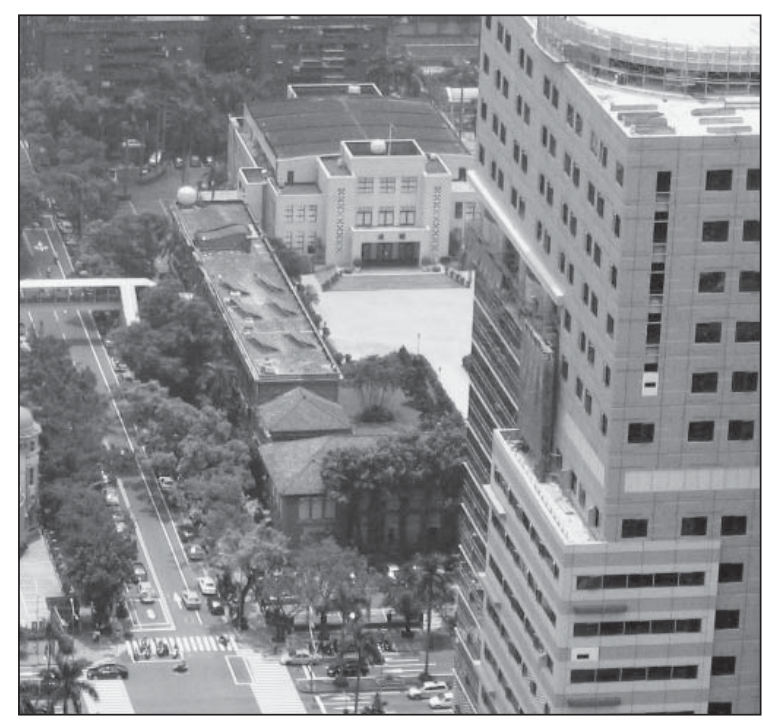
el estilo Hebei con Sun

Lutang en el Instituto Central de Artes Marciales, establecido en Nanjing en 1927 (Green \& Saint, 2003: 23-24), y el Sr. Zhou Jichun (Jian Nan), quien era el historiador del grupo (Smith, 1974: 113-121). En 1972 el Dr. Wu emigró a Río de Janeiro, Brasil, donde fundó en Instituto Cultural Chino y enseñó hasta su muerte. Goza de un gran seguimiento en Brasil, donde se le consideraba como un embajador de la cultura china. Entre sus muchos estudiantes figura Nelson Ferreira, cabeza de la Asociación Zhong Yi Kung Fu en Madison, Wisconsin. 


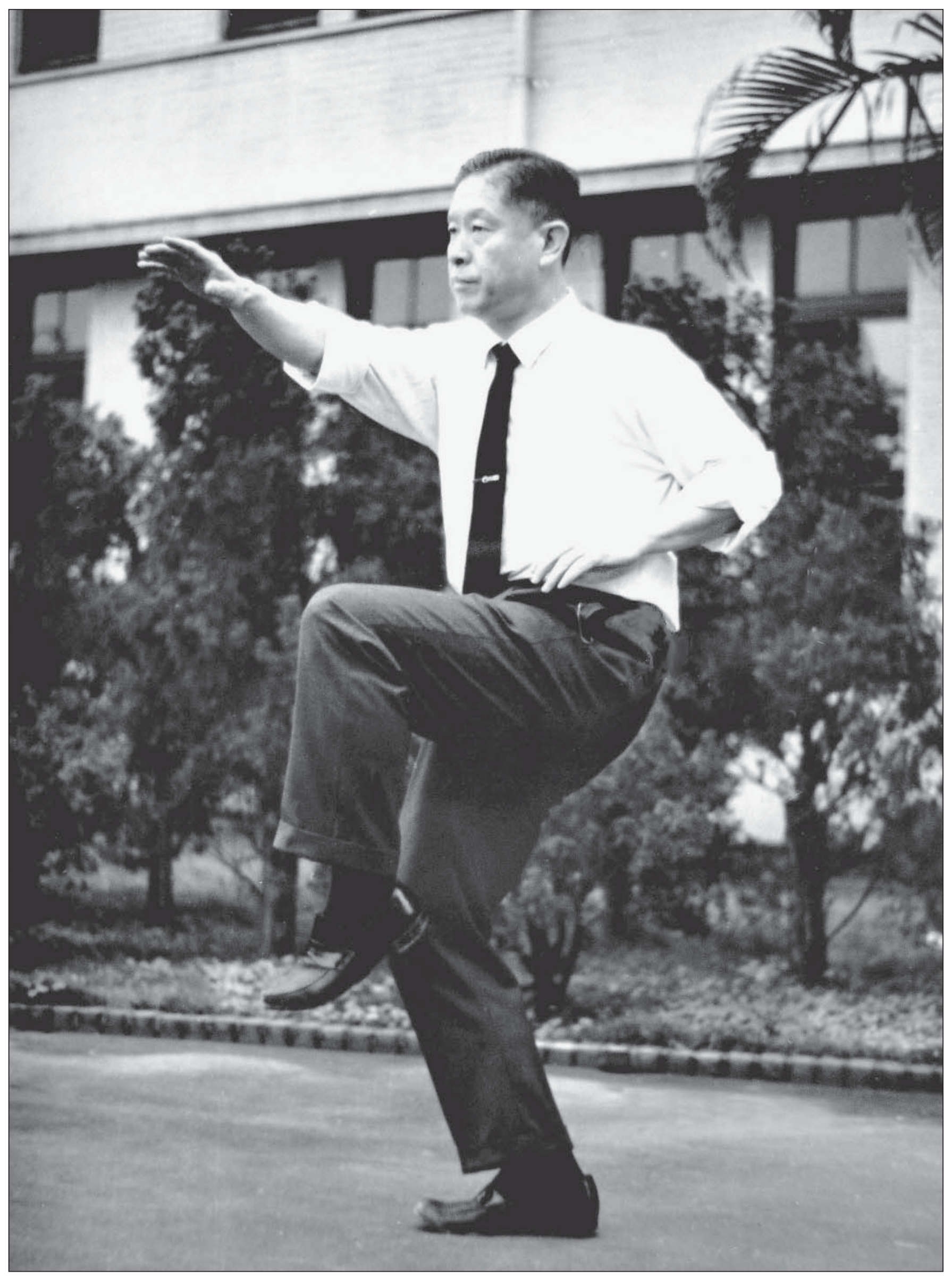




\section{El estilo clásico Shanxi Che}

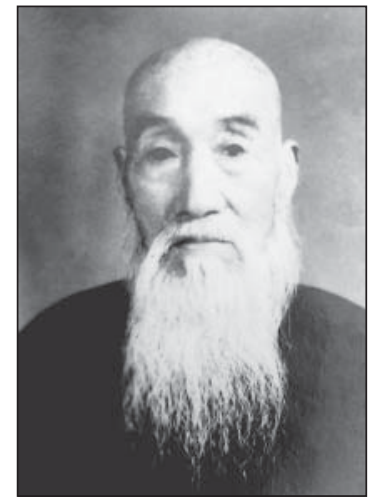

Bu Xuekuan (1876-1971), profesor del Dr. Wu.

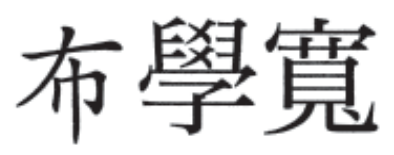

Posición de Tres Puntos.
El estilo original del Xingyiquan estilo Sanxi Che se muestra de un modo muy claro y sencillo, especialmente comparándolo con algunas de las versiones "mejoradas" del Xingyiquan para la representación, desarrolladas recientemente para acomodarse a las demandas del programa deportivo oficial y a las preferencias populares de una sociedad china en rápida evolución. El estilo Che se orienta hacia el pragmatismo. Se dice que Bu Xuekuan, el profesor del Dr. Wu, afirmó: "La técnica de combate se basa por completo en el flujo de energía interna, una combinación única de fuerza esférica, potencia elástica y la respuesta instantánea de liberación de fuerza y control del oponente". El creía en seleccionar las mejores técnicas que habían exhibido otras personas de la comunidad de las artes marciales, y fue conocido por su "mano de león que devora" (shi tun shou) (Shanxi Wenshi, 1992: 305).

Desde el comienzo, los estudiantes del Dr. Wu pasaban una considerable cantidad de tiempo perfeccionando la fundamental y estable Posición de Tres Puntos (santi shi), que da origen a todas las formas y rutinas. Esta posición enfatiza los elementos esenciales de la postura, equilibrio y coordinación necesarios para emitir y manejar la fuerza de un modo efectivo. Representa la combinación simultánea de la defensa y el ataque y es una manifestación visible del cultivo personal de las tres combinaciones internas (mente, energía y fuerza) y de las tres combinaciones externas (hombros y cintura, codos y rodillas, y pies y manos), es decir, las seis combinaciones (liuhe) (Wu, 1969, Vol. 36:44) ${ }^{1}$. De hecho el Boxeo de las Seis Combinaciones (Liuhequan) fue uno de los primeros nombres para lo que desde entonces ha venido a llamarse Xingyiquan.

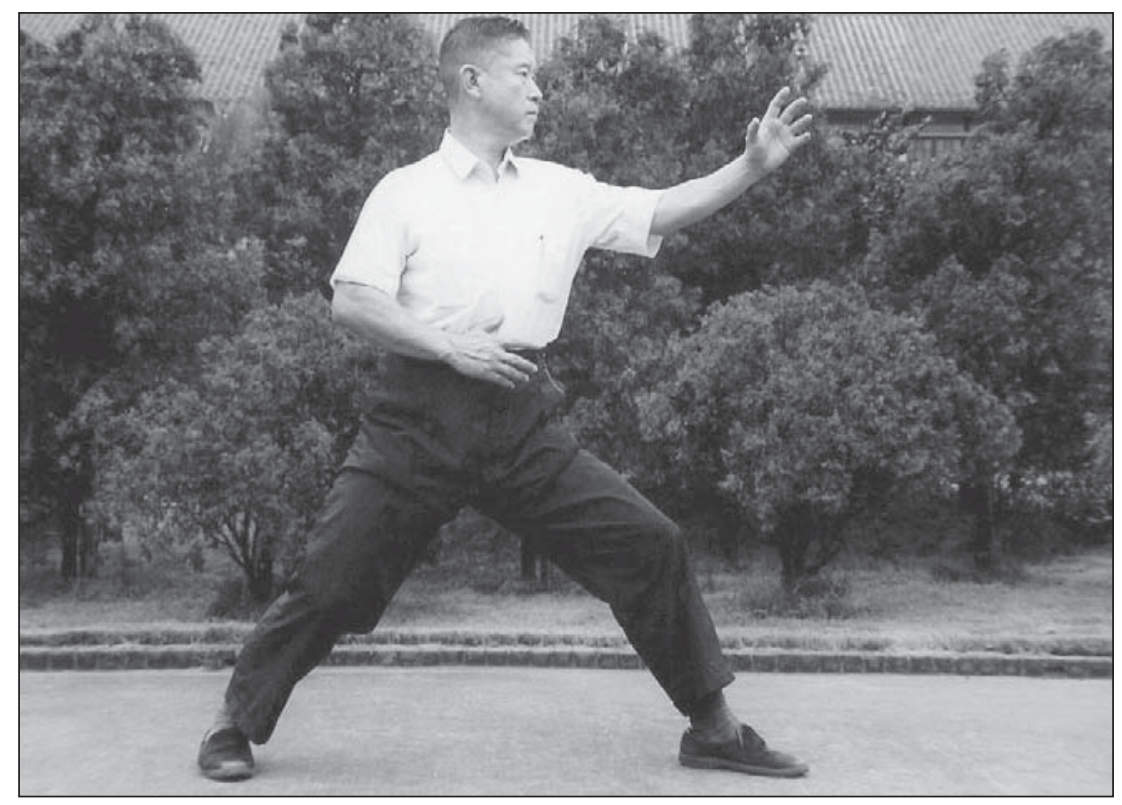

El Dr. Wu también enseñaba otras dos posiciones, la Posición del Vacío Supremo (wuji shi) y la Posición del Principio Vital (hunyuan zhuang). La primera antecede a la Posición de Tres Puntos, mientras que la segunda se practica para focalizar la energía mentalmente y dirigir la fuerza tal y como se refleja en la frase "puño pero sin puño, objetivo pero sin objetivo, en medio del no objetivo está el objetivo" (Sun, 1970b: 28). El estudiante debe llegar a sus propias conclusiones cuando interpreta este tipo de frases. Mi punto de vista es que se refiere a desarrollar la espontaneidad como respuesta a la liberación de fuerza por parte de un oponente. Exige una mente clara, centrada en la situación del momento. 


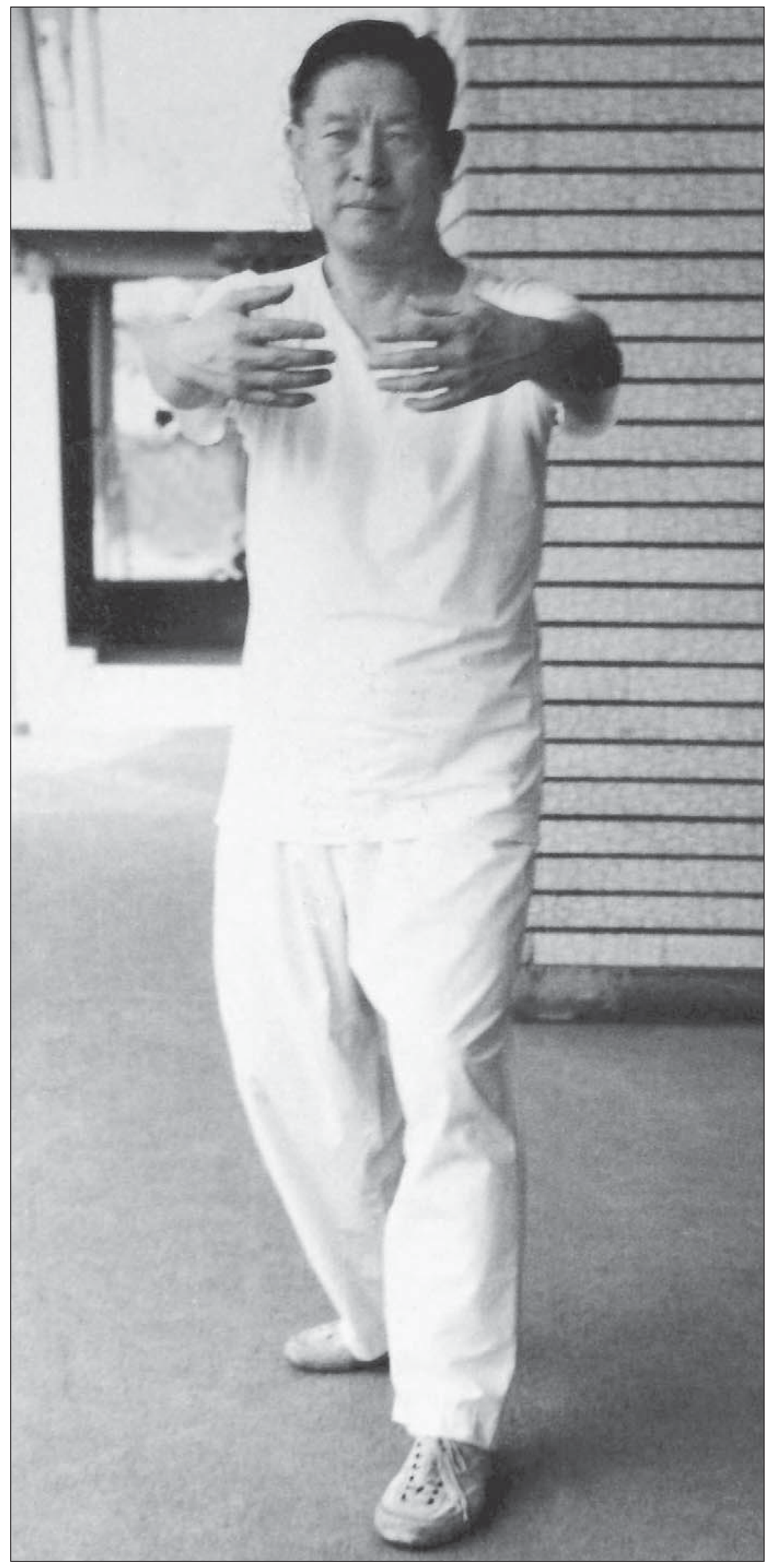

"La técnica de combate se basa por completo en el flujo de energía interna, una combinación única de fuerza esférica, potencia elástica y la respuesta instantánea de liberación de fuerza y control del oponente".

La Posición del Principio Vital. 
Desde la Posición de Tres Puntos, los estudiantes continúan estudiando las formas de los Cinco Elementos: metal/cortar, madera/aplastar, agua/perforar, fuego/explotar, y tierra/cruzar. Huelga decir que estas son descripciones imperfectas de las técnicas, que sólo llegan a estar claras con la práctica real. Después de practicar las formas individuales de los Cinco Elementos, los estudiantes las unen con la rutina individual Lianhuan y después practican dos rutinas por parejas llamadas Pequeño Mazo de las Cinco Flores y Mazo de los Cinco Elementos, las cuales ponen en oposición las técnicas de uno contra las del otro. Sin embargo, aparte de estas dos rutinas por parejas, los estudiantes no hacían hincapié en una interacción dogmática entre los Cinco Elementos, puesto que ello habría condicionado la flexibilidad de mente/intención propia del Xingyiquan.

\section{El Dr. Wu y los Cinco Elementos}

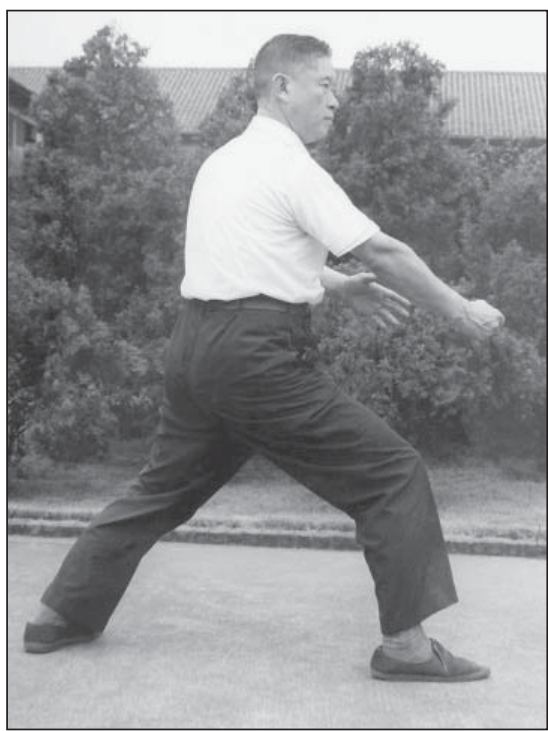

Metal/Cortar

Cinco Elementos 五行

$\begin{array}{ll}\text { Metal 金 } & \text { Cortar 䢃 } \\ \text { Madera 木 } & \text { Aplastar 崩 } \\ \text { Agua 水 } & \text { Perforar 鑽 } \\ \text { Fuego 火 } & \text { Explotar 炮 } \\ \text { Tierra 土 } & \text { Cruzar 橫 }\end{array}$

Fuego/Explotar

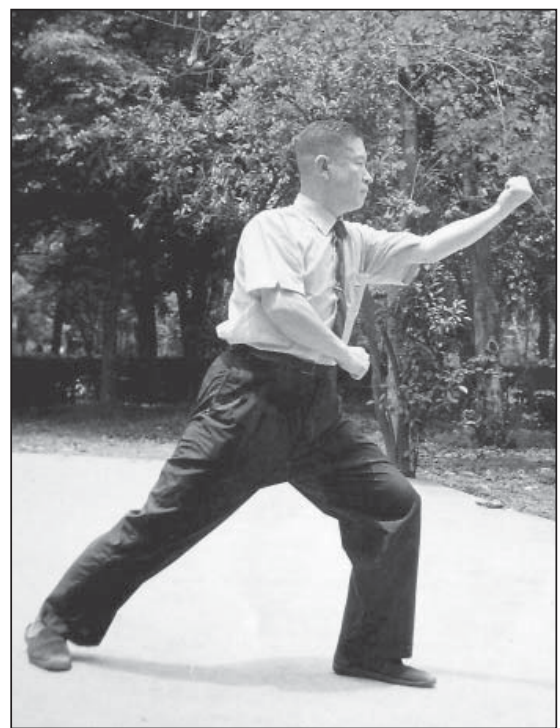

Agua/Perforar

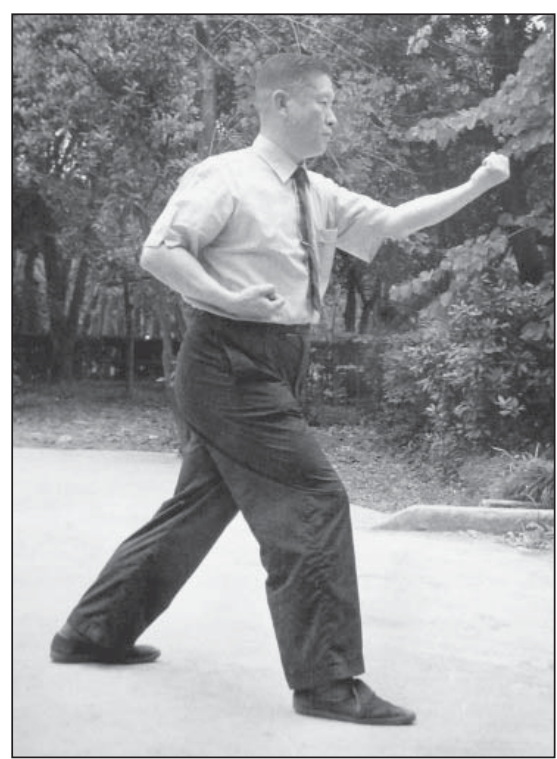

Tierra/Cruzar 


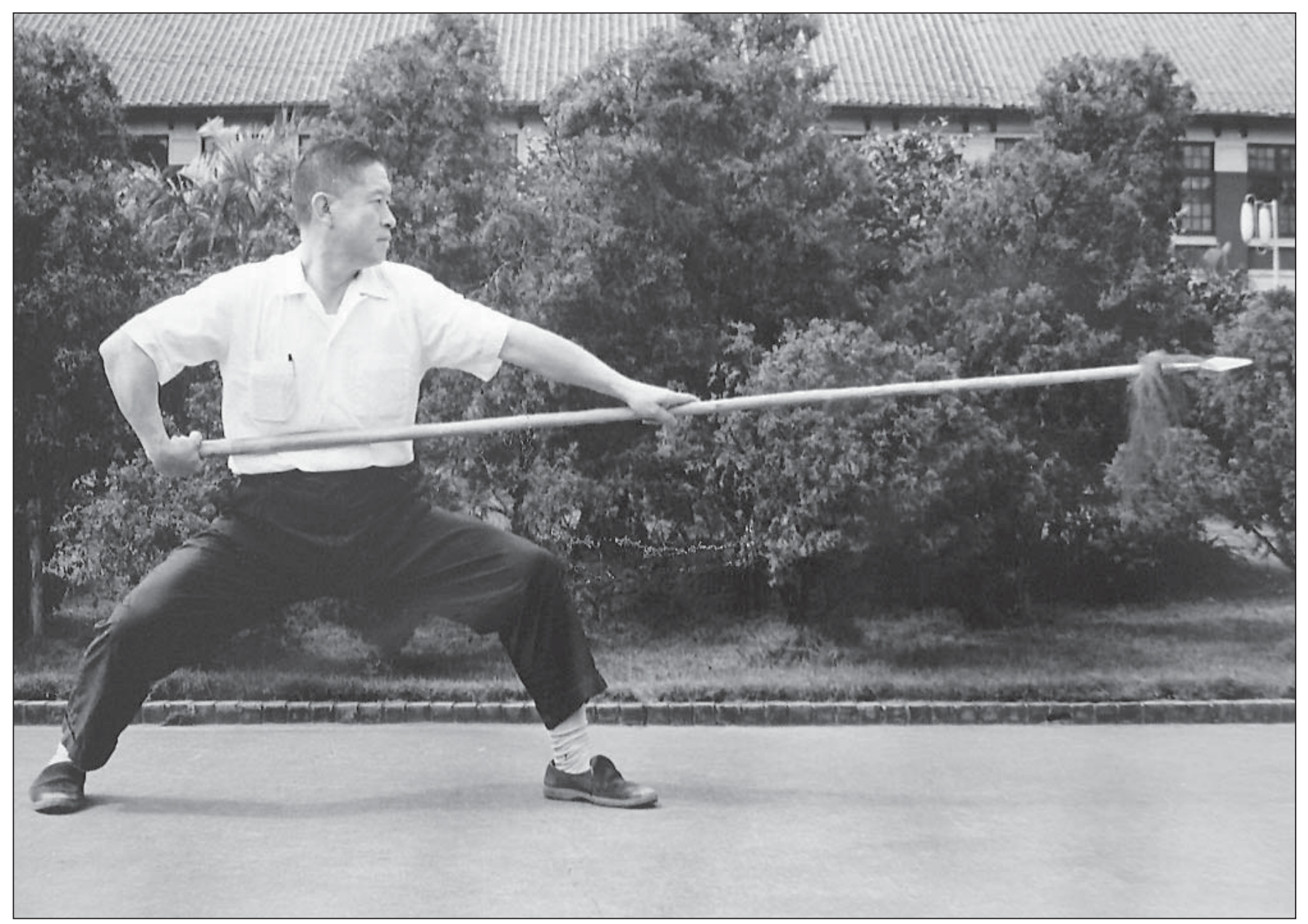

El Dr. Wu demostrando a su clase técnicas de lanza.

El Dr. Wu enfatizaba el control como un importante principio. Los estudiantes practicaban agarres/sujeciones, particularmente en las muñecas y codos, como técnica de combate esencial del Xingyiquan, clave para controlar a un oponente y realzar la efectividad de la propia liberación de energía, y un reflejo de la técnica "mano de león que devora" de Bu Xuekuan (Yang, 1984), donde la fuerza simultánea de agarrar y tirar con una mano refuerza el impulso del luchador para golpear con la otra. El Dr. Wu también ejecutaba su forma del Corte con un puño cerrado y un movimiento de torsión, combinación que incrementa la efectividad de la forma. La torsión durante el contacto incrementa el efecto sobre el objetivo y, al mismo tiempo, reduce el impacto sobre el luchador.

Los estudiantes complementaban la forma de los Cinco Elementos con el entrenamiento con la lanza. Una fuente temprana (aprox. 1735) relata cómo un miembro de la familia Shanxi Ji (ahora conocida como Ji Longfeng) desarrolló el Liuhequan a partir de técnicas de lanza existentes como medio de defensa en tiempos de paz (Wu, 2000: 9). Una visión más común, que expresan otros, incluyendo al general Qi Jiguang de la Dinastía Ming, es que los estilos de boxeo a manos desnudas se consideraban como la base para la práctica con armas. Sin embargo, cuando uno llega a familiarizarse con la forma de los Cinco Elementos, puede discernir claramente una relación, sin preocuparse si fue primero el boxeo o la lanza. La práctica de la lanza ayuda a la coordinación de brazos, piernas y cintura, o del movimiento de todo el cuerpo (no sólo de su parte superior), desarrollando la liberación de fuerza. 
Desde los Cinco Elementos, los estudiantes siguen con la práctica de las formas de los Doce Animales, comunes a los estilos Shanxi y Hebei: Dragón, Tigre, Mono, Caballo, Serpiente, Gallo, Golondrina, Halcón, Caimán, Tai², Águila y Oso. Cada uno de estos animales se corresponde con características de combate reales y derivadas de los mismos, y, de nuevo, uno puede modificar tales interpretaciones a través de la observación y la práctica:

Dragón 龍 Actúa de modo ondulante para agarrar y proyectar al oponente Tigre 虎 Acecha y se abalanza sobre su presa.

Mono 猴 Es ágil y rápido.

Caballo 馬 Golpea con ambos cascos.

\section{El Dr. Wu y los Doce Animales}

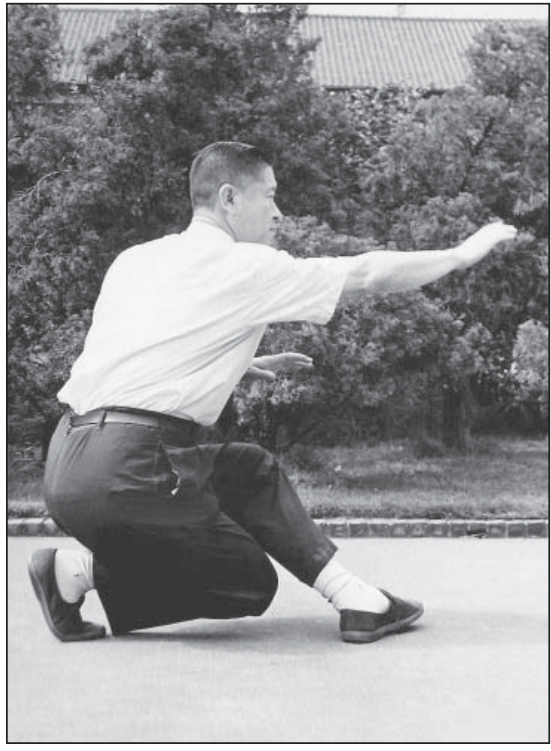

Dragón

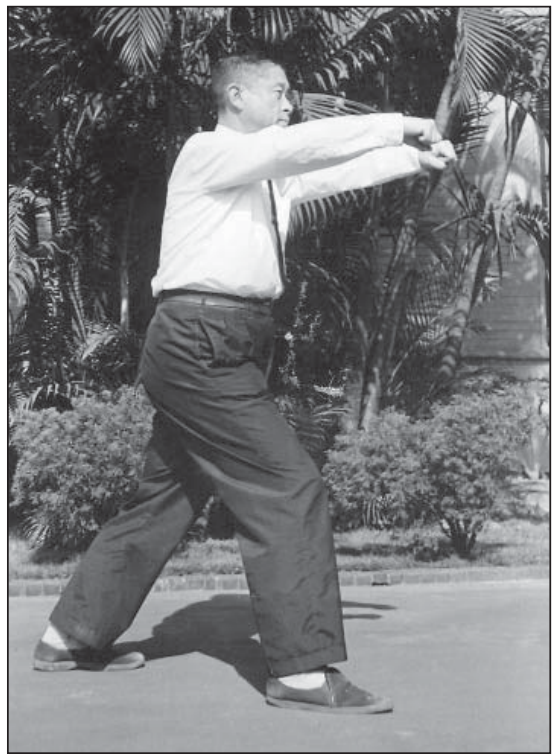

Caballo

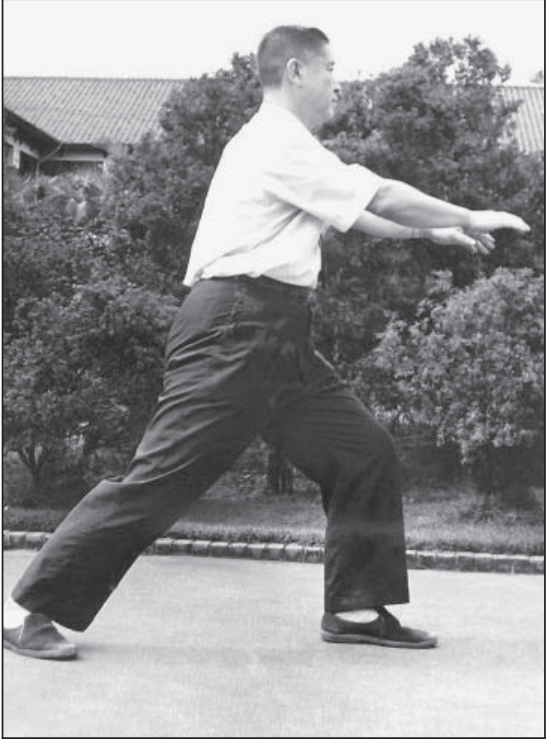

Tigre

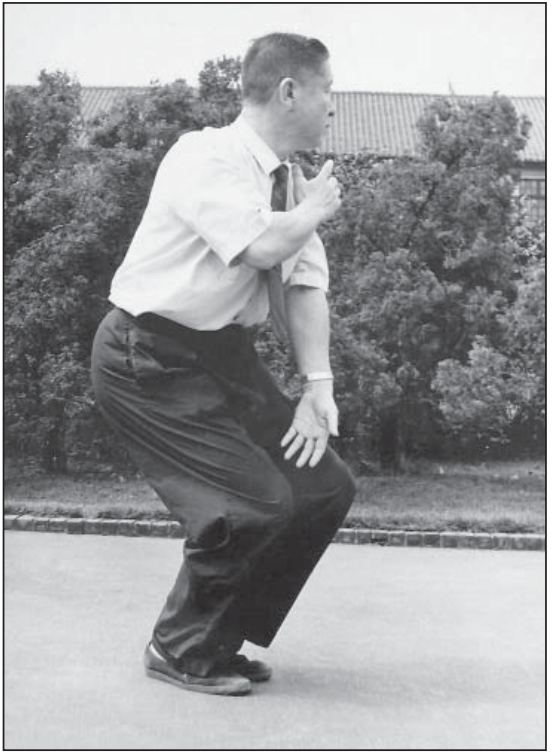

Serpiente

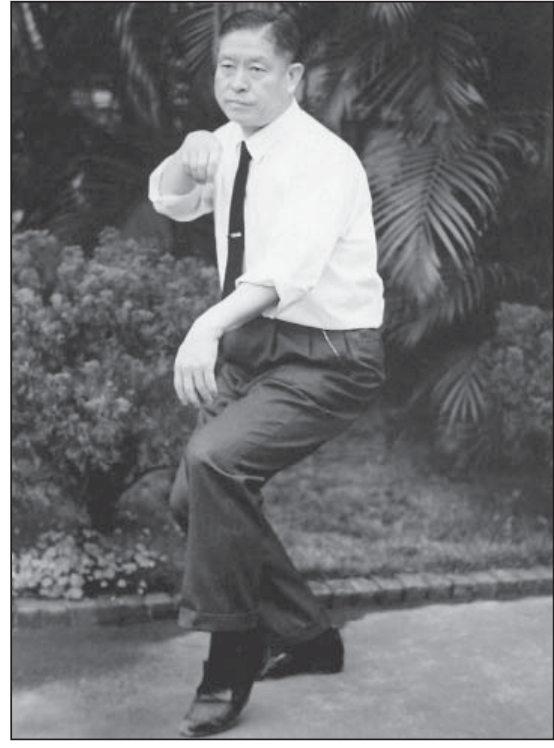

Mono

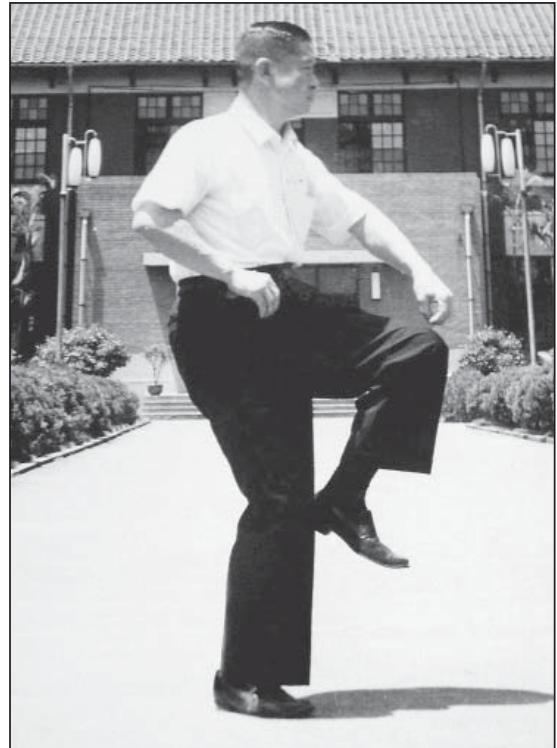

Gallo 
Serpiente 蛇 Se abre paso como separando la hierba en su camino.

Gallo Desarrolla una actitud combativa multifacética.

Golondrin 燕 Baja en picado y luego sube.

Halcón 鶷 Puede abalanzarse y golpear desde un flanco.

Caimán 罬 Exhibe fuerza en sus antebrazos y codos.

Tai 媓 Combina un barrido para desviar y empuja con ambos puños.

鮐 (versión de Wu Diank)

Águila 鶋 Agarra despiadadamente a su presa

Oso 熊 Es estable y da golpes repentinos o aplasta a sus oponen tes $^{3}$.

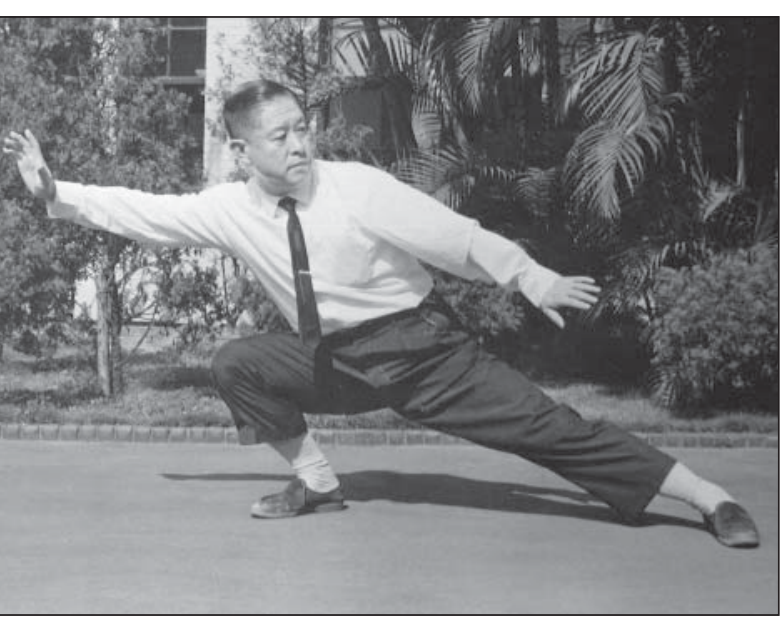

Golondrina

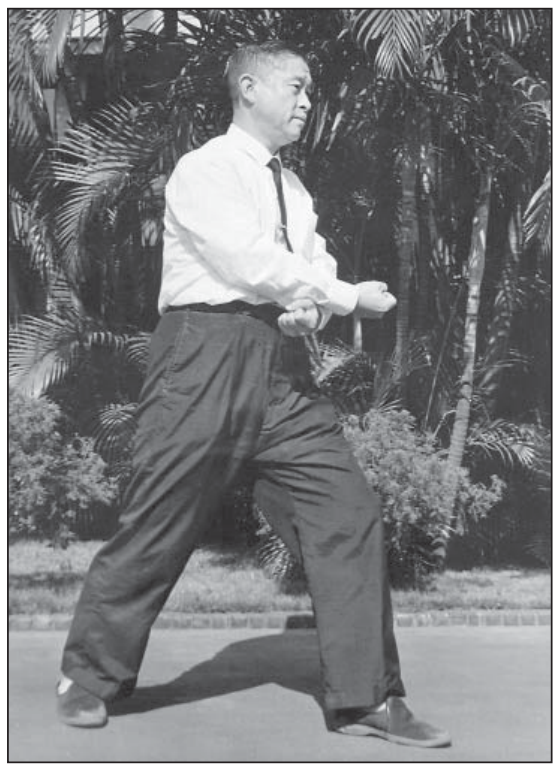

Tai

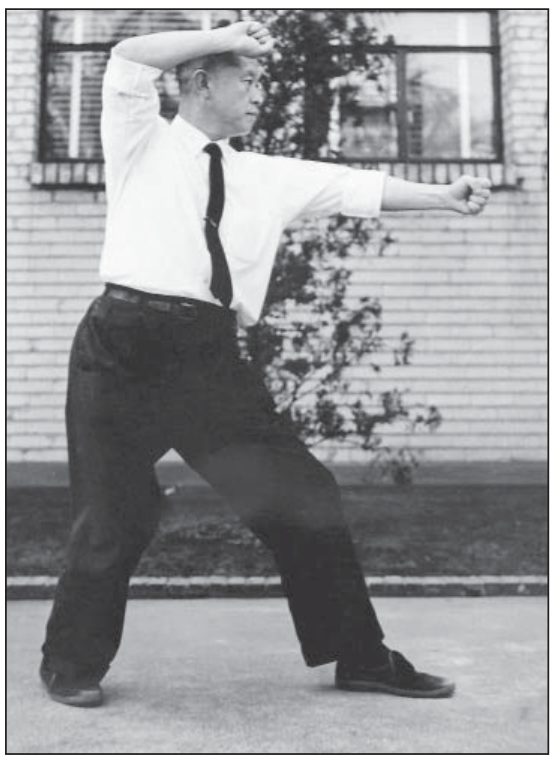

Halcón

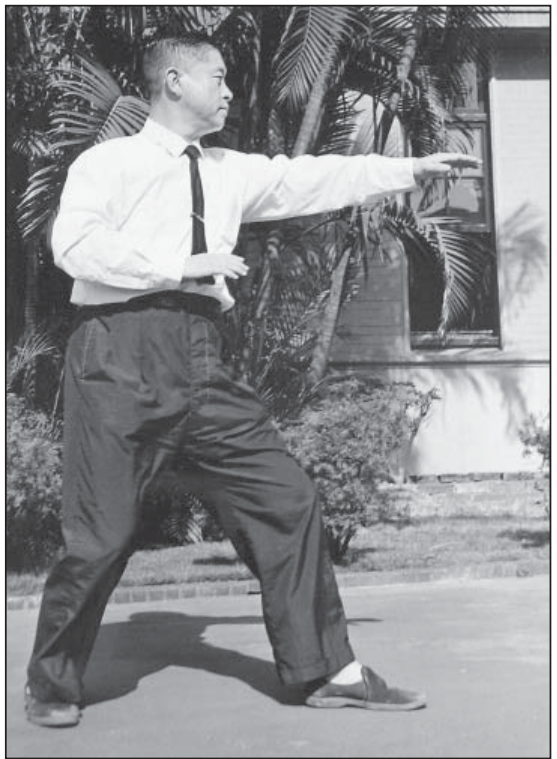

Águila

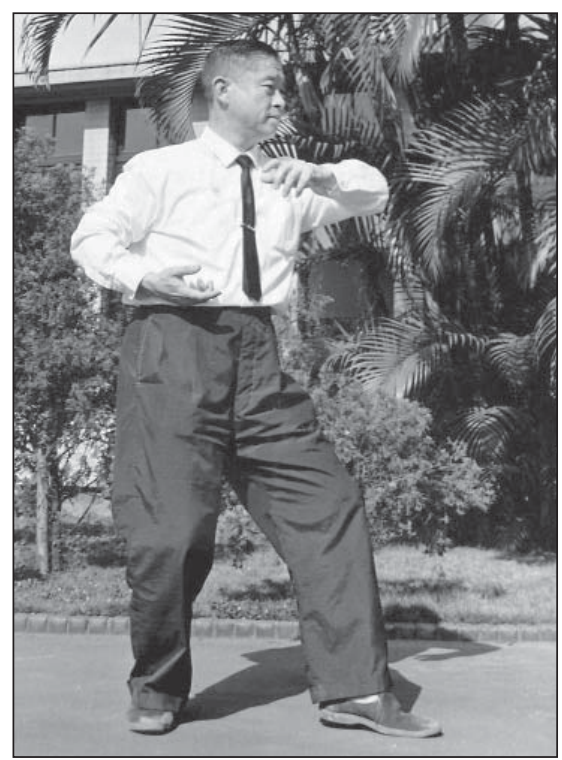

Caimán

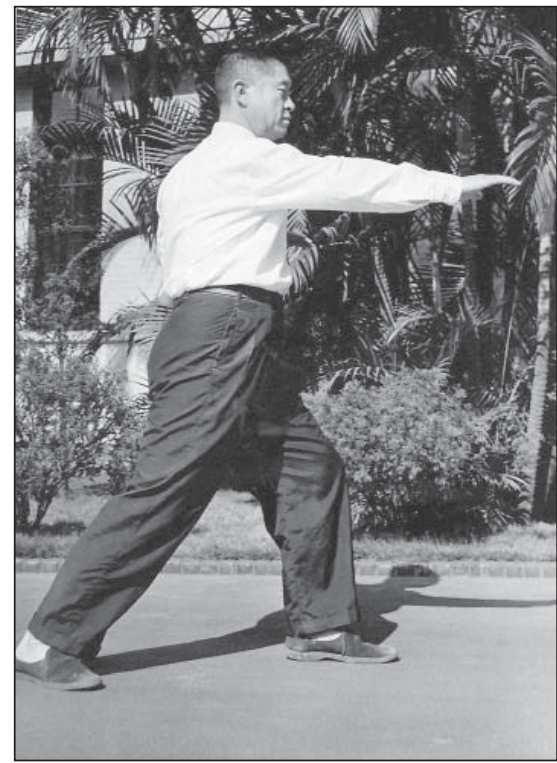

Oso 
El autor estudiando con el Dr. Wu la rutina del Xingyi por parejas Mazo

Protector, a principios de los años setenta. En esta mini-secuencia en Dr.

Wu ataca, primero bloqueando hacia abajo con su mano izquierda mientras simultáneamente da una patada al atacante en la espinilla, para a continuación dar un pisotón para incapacitar y evitar

la escapatoria mediante un golpe con la palma de la mano en la frente.
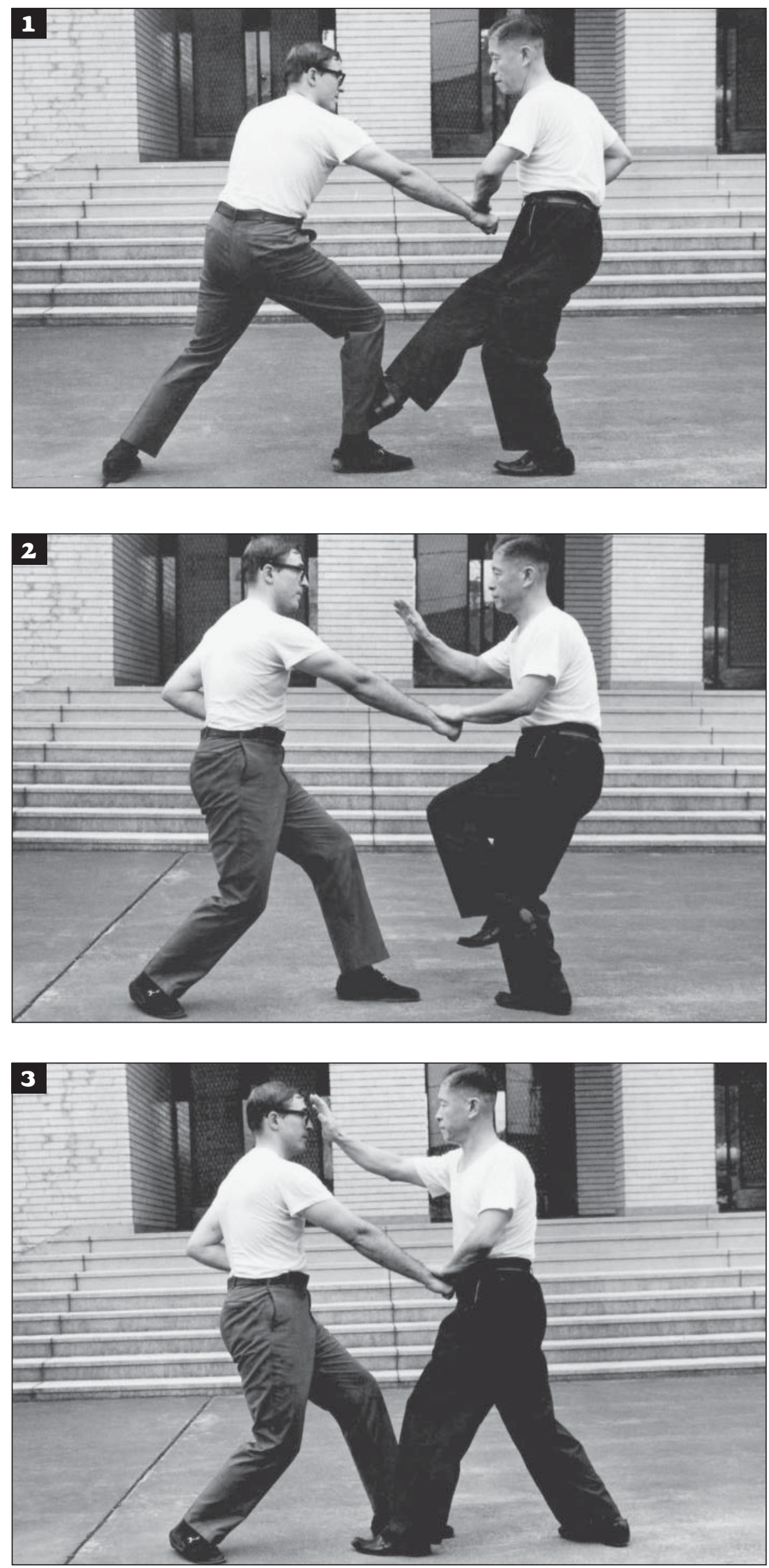

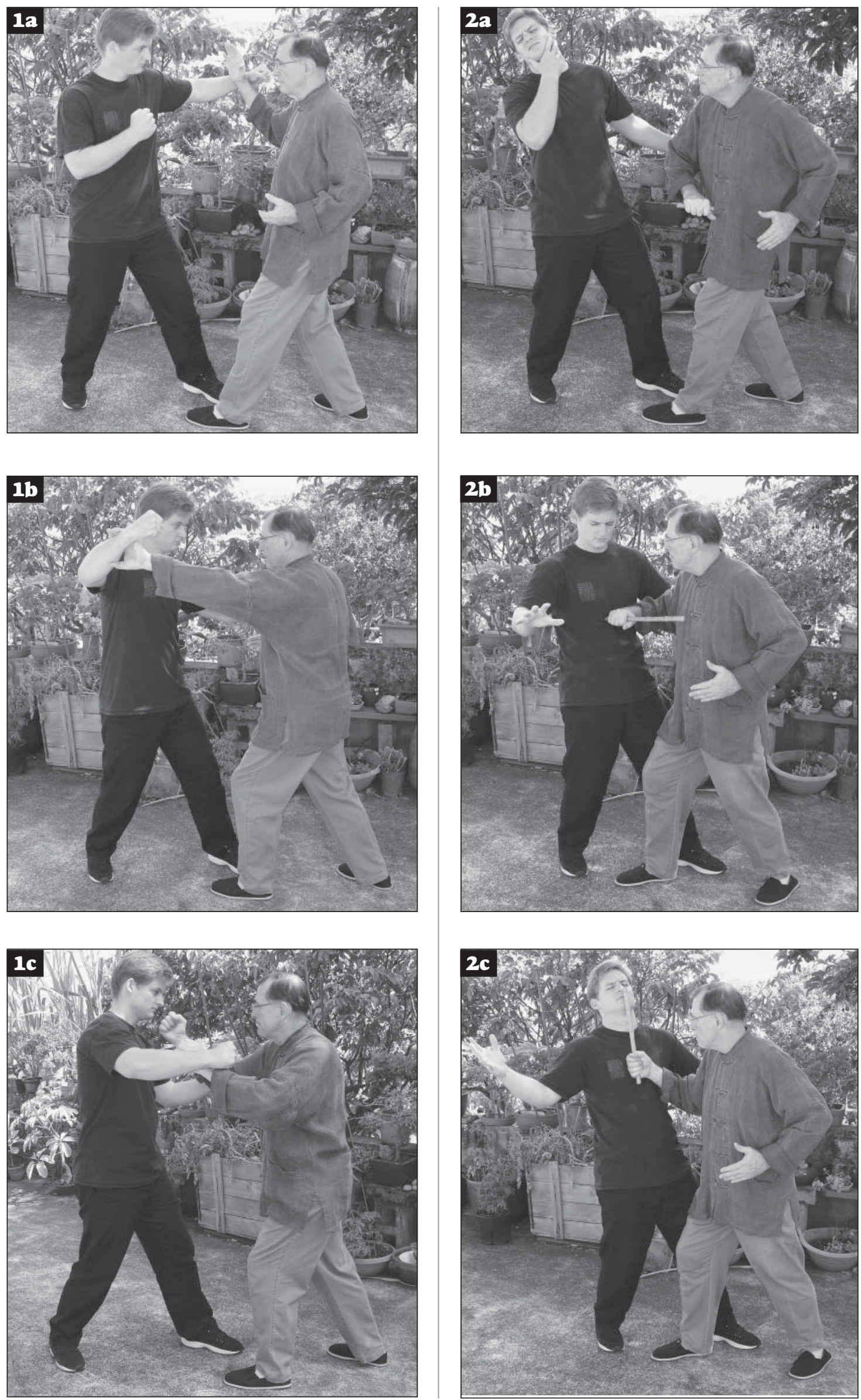

"Tres puños, dos finales", técnica basada en el modo en que un conductor de carros de mulas utiliza el mango de un látigo corto. 
Los estudiantes practicaban las formas de los Doce Animales del mismo modo que las formas de los Cinco Elementos, excepto el Gallo, que exigía una corta rutina individual denominada las Cuatro Técnicas de la Forma del Gallo. Posteriormente, los estudiantes aprendían la Rutina Individual de los Doce Animales o Forma de la Mezcla del Puño (Za Shi Chui), y finalmente la Rutina por Parejas de los Doce Animales o Mazo Protector (An Shen Pao).

Como una de sus técnicas de combinación favoritas, el Dr. Wu también describía "tres puños, dos finales" (san quan liang ba), como defensa práctica basada en cómo un conductor de mulas de Shanxi utilizaba el mango de un látigo corto. "Tres puños" consiste en una rápida secuencia derecha-izquierda-derecha. Los dos primeros golpes son dos desvíos en forma de barrido para limpiar el camino para el tercero, que es el puñetazo hacia el interior. Los "dos finales" representan los dos finales del mango del látigo del conductor del carro. El movimiento consiste en un golpe seco con una mano y un golpe súbito, es decir, un golpe en el plexo solar con la mano en posición inversa utilizando el extremo corto del mango y un giro rápido hacia arriba para dar un golpe repentino en la cara con el extremo largo de del mango.

Aprender Xingyiquan con el Dr. Wu fue una experiencia inolvidable para conocer y comprender al ser humano y para familiarizarme con un elemento fascinante de una de las culturas más antiguas del mundo. En un análisis final, ni un libro, ni mucho menos un artículo, abrirá realmente las puertas hacia este u otro estilo de artes marciales. Los verdaderos secretos sólo se revelan a través de la interacción humana y de la comprensión individual.

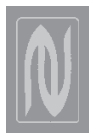

\section{Notas}

1 Lo que sigue es otra forma más colorista de describir las Seis Combinaciones, según se encuentra en los manuales: Piernas de Gallo, Cuerpo de Dragón, Patas Delanteras del Oso, Agarre del Águila, Abrazo del Tigre, y Sonido del Trueno (lei sheng) (como el kiai o gritos propios del kárate japonés, los artistas marciales chinos también emitían sonidos en la proyección de fuerza (Bao, 1971: 40; Jiang, 1970a: 8-9). De acuerdo con Jiang Rongqiao, a principios del s. XX los profesores abandonaron el "sonido del trueno" por ser poco culto. Sin embargo, el Sonido del Trueno, o "kiai" (unión de los caracteres chinos qi -energía vital- y he -unidad-), como aún se denomina en japonés, era considerado como un importante fenómeno psico-fisiológico, un factor en la focalización de la energía vital en la emisión de fuerza y, al mismo tiempo, podía distraer al oponente.

2 El Tai es algo así como un animal misterioso. Se dice que era un ave que se extinguió. La última versión "oficial" señala que es un pez (Wu, 2000: 186). Sin embargo, la única explicación con sentido es la descripción del movimiento de la forma: ambos puños, colgando con naturalidad, se balancean juntos, se cruzan, suben por encima de la frente, se separan y se balancean hacia fuera y abajo, y (1) se cruzan de nuevo al nivel de la cintura, con los puños hacia arriba, o (2) con los puños juntos y arriba, pero sin cruzarse, vuelven juntos al nivel de la cintura.

3 El estilo Henan tiene solamente diez animales: Dragón, Tigre, Mono, Caballo, Serpiente, Gallo, Golondrina, Halcón, Águila y Gato. El estilo Henan añade el Gato, pero quita el Tai, el Caimán (el pequeño caimán chino actualmente está casi extinguido) y el oso. Sin embargo, el proponente del estilo Henan, Bao Xianting, demuestra un cierto número de combinaciones Águila-Oso en su libro (Bao, 1971: 46). Por otro lado, yo 
practiqué un movimiento/técnica en la rutina individual Lianhuan llamado Gato Salvaje Trepa al Árbol (Li Mao Shang Shu) (Sun, 1970a: 40-42). Por tanto, existen algunas claras excepciones a las descripciones generales de lo que constituye el cuerpo de los varios estilos de Xingyiquan.

\section{Glosario}

$\begin{array}{rlr}\text { An Shen Pao } & \text { 安身炮 } & \text { San Quan Liang Ba 三拳兩把 } \\ \text { Hun Yuan Zhuang } & \text { 渾元椿 } & \text { San Ti Shi 三體勢 } \\ \text { Kiai } & \text { 氣合い } & \text { Shi Tun Shou 獅吞手 } \\ \text { Ji Longfeng } & \text { 姬龍峰 } & \text { Wu Ji Shi 無極勢 } \\ \text { Lei Sheng } & \text { 雷聲 } & \text { Xing Yi Quan 形意拳 } \\ \text { Li Mao Shang Shu } & \text { 狸貓上樹 } & \text { Za Shi Chui 雜式捶 } \\ \text { Liu He } & \text { 六合 } & \end{array}$

\section{Bibliografía - China}

Bao Xianting (1971). Xingyiquan manual.

Jiang Rongqiao (1970a). Illustrated Xingyi mother boxing.

Jiang Rongqiao (1970b). Xingyi mixed form pounder-eight form fist combined.

Shanxi Literature \& History Editorial Committee (1992). Shanxi literature and history selections.

Sun Fuquan (1970a). Xingyiquan study.

Sun Fuquan (1970b). Discussion of the true meaning of boxing.

Wu Chaoxiang (1972). The way to a strong body.

Wu Chaoxiang (1971). Brief introduction to Xingyiquan.

Wu Chaoxiang (1969). Xingyiquan's basic techniques.

Wu Dianke (2000). Complete Xingyiquan.

Yang Jisheng (1984, April). Shanxi Xingyiquan duo practice: Six methods of free fighting.

Yang Yingguang (1985). Shanxi Che school of Xiangyiquan.

寶顯廷 (1971). 《形意拳譜》1936, 台北：中華武術出版社。

姜容樵 (1970a). 《寫真形意母拳》1930, 台北：中華武術出版社。

姜容樵 (1970b). 《形意雜式捶。八式拳合刊》1930, 台北：中華武術出版社。

山西文史 (1992). 山西文史資料編輯編《山西文史精選》

Vol. 10, 太原: 山西高校聯合出版社。

孫福全 (1970a). 《形意拳學》1915, 台北: 中華武術出版社。

孫福全 (1970b). 《拳意述真》1924, 台北: 中華武術出版社。

武朝相 (1972). 《強身之道》台北: 中華武術出版社。

武朝相 (1971). 「形意拳簡介」《武壇》第一卷, 第五期, 13 。

武朝相 (1969). 「形意拳的基本功夫」上中下《太極拳研究專集》

第三十四，三十六，三十九期，台北：中華書局。

吳殿科主編 (2000). 《形意拳術大全》太原：山西人民出版社。

楊吉生口述, 張青貴, 張希貴整理 (1984 Abril). 『山西形意拳對練：

散手六法」《搏擊》34: 16-17, 20.

楊映光, 杜世秀整理 (1985). 《山西車派形意拳》太原：山西人民出版社。 